IRA-International Journal of Technology \& Engineering ISSN 2455-4480

Proceedings of the International Conference on Science \& Engineering for Sustainable Development (2017)

Pg. no.202-213

Published by: Institute of Research Advances https://research-advances.org/index.php/IRAJTE

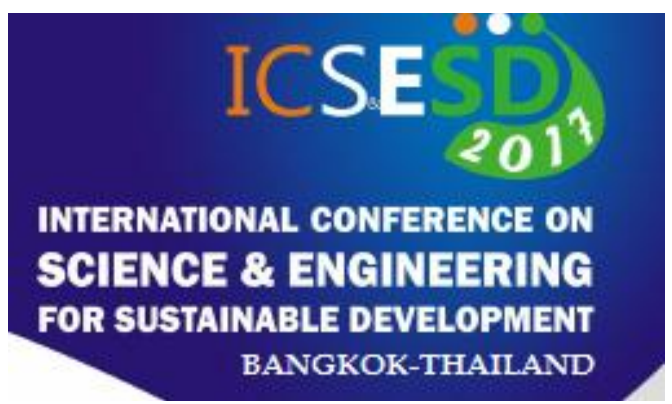

\title{
A Review on Membrane Bioreactor (MBR) Technology: It's Commercial Applications And Possibilities of Hybridization with other Membrane Techniques to Recover Valuable Industrial By- Products for Sustainable Development and Environmental Protection by and Large
}

\author{
Ajay P. Pardey ${ }^{1}$, Dr. V. S. Sapkal ${ }^{2}$, Dr. R. S. Sapkal ${ }^{3}$ \\ ${ }^{1}$ Assistant Professor, Deptt.of Chemical Engg., JDIET, Yavatmal. Pin.: 445001, Maharashtra, India. \\ (email.: ajayppardey@ rediffmail.com, Cell No.: +91 9763702589) \\ ${ }^{2}$ Professor \& Head, Deptt.of Chemical Technology, SGBAU, Amravati, India. \\ ${ }^{3}$ Professor, Deptt.of Chemical Technology, SGBAU, Amravati, India.
}

Type of Review: Originality Check \& Peer Review under the responsibility of the Scientific Committee of the Conference and The Institution of Engineers (India).

DOI: http://dx.doi.org/10.21013/jte.ICSESD201720

\section{How to cite this paper:}

Pardey, A., Sapkal, V., Sapkal, R. (2017). A Review on Membrane Bioreactor (MBR) Technology: It's Commercial Applications And Possibilities of Hybridization with other Membrane Techniques to Recover Valuable Industrial By-Products for Sustainable Development and Environmental Protection by and Large. Proceedings of the International Conference on Science \& Engineering for Sustainable Development (2017), 202-213. doi: http://dx.doi.org/10.21013/ite.ICSESD201720

(C) International Conference on Science \& Engineering for Sustainable Development \& The Institution of Engineers (India).

\section{(cc) EY-NC}

This work is licensed under a Creative Commons Attribution-Non Commercial 4.0 International License subject to proper citation to the publication source of the work.

Disclaimer: The conference papers as published by the Institute of Research Advances (IRA) are the views and opinions of their respective authors and are not the views or opinions of the IRA. The IRA disclaims of any harm or loss caused due to the published content to any party. 


\section{ABSTRACT}

Membrane bioreactor (MBR) technology is advancing rapidly around the world both in research and commercial applications. Despite the increasing number of studies and full-scale applications of MBR systems, directions and trends in academic research as well as commercial developments require further analysis. This paper aims to critically characterize and review worldwide academic research efforts in the area of MBRs as well as focus attention to commercial MBR applications. Various research papers published in peer-reviewed international journals were used as the database for the analysis provided in this paper. After a surge of MBR publications, research appears to have reached a plateau in the last 7 years using both submerged and external MBR units. Although much of the pioneering research occurred in Japan, France and the UK, countries such as South Korea, China and Germany have significantly contributed to the research pool in the last 5 years. The primary research focus has been on water filtration MBRs with limited growth in extractive and gas diffusion MBRs which still hold un-tapped potential. Fundamental aspects studied in academic research predominantly involve issues related to fouling, microbial characterization and optimizing operational performance. Zenon occupies the majority of the MBR market in America, whereas Kubota and Mitsubishi-Rayon has a larger number of installations in other parts of the world. Due to more stringent regulations and water reuse strategies, it is expected that a significant increase in MBR plant capacity and widening of application areas will occur in the future. Potential application areas include nitrate removal in drinking water treatment, removal of endocrine disrupting compounds from water and wastewater streams; enhancing bio-fuels production via membrane assisted fermentation and gas extraction and purification MBRs. Treatment technology for water recycling encompasses a vast number of options. Membrane processes are regarded as key elements of advanced wastewater reclamation and reuse schemes and are included in a number of prominent schemes world-wide, e.g. for artificial groundwater recharge, indirect potable reuse as well as for industrial process water production. Membrane bioreactors (MBRs) are a promising process combination of activated sludge treatment and membrane filtration for biomass retention.

Many researchers have concluded that wastewater reclamation in intended MBR technology is the method of choice when it is combined with other advanced treatment technologies.

As water shortages are increasing, the need for sustainable water treatment and the reuse of water is essential. Water reuse from wastewater can be accomplished in a membrane bioreactor (MBR) in the secondary activated sludge stage of a wastewater treatment plant. To remove viruses, dissolved organics and in organics still present in the MBR permeate, nanofiltration $(N F)$ can be applied. Nevertheless, the major drawback of nanofiltration membranes is the production of a concentrate stream that cannot be discharged to the environment. The research show that the continuous production of reusable water from wastewater in a combined MBR and NF process with NF concentrates recirculation can be successful.

Keywords -Wastewater reclamation; Water reuse; Membrane bioreactors; Trace pollutants; Membrane bioreactor; Wastewater treatment; Commercial application; Critical review; Membrane fouling; Nano filtration; Concentrates.

\section{INTRODUCTION}

Membrane bio-reactor (MBR) technology combines the biological degradation process by activated sludge with a direct solid-liquid separation by membrane filtration. By using micro or ultra filtration membrane technology (with pore sizes ranging from 0.05 to $0.4 \mu \mathrm{m}$ ), MBR systems allow the complete physical retention of bacterial flocs and virtually all suspended solids within the bioreactor. As a result, the MBR has many advantages over conventional wastewater treatment processes. These include small footprint and reactor requirements, high effluent quality, good disinfection and odor 
control capability, higher volumetric loading and less sludge production. As a result, the MBR process has now become an attractive option for the treatment and reuse of industrial, domestic and municipal wastewaters, as evidenced by their constantly rising numbers and capacity. [6]

A MBR combines the activated sludge process with a membrane separation process. The reactor is operated similar to a conventional activated sludge process but without the need for secondary clarification and tertiary steps like sand filtration. Low-pressure membrane filtration, either microfiltration (MF) or ultra filtration (UF), is used to separate effluent from activated sludge. The two main MBR configurations involve either submerged membranes or external circulation (side-stream configuration). [7]

Original research on MBR technology for various industrial wastewater treatments is becoming a hot topic, and the application areas include food-processing wastewater, petrochemical wastewater, hospital wastewater, printing and dyeing wastewater, slaughterhouse wastewater, etc. MBR systems combined with pretreatment anaerobic biological process and/or with post-treatment steps like nanofiltration (NF) were commonly used in landfill leachate treatment in order to achieve good effluent quality. [10]

Nano-Filtration membranes have properties between those of reverse osmosis (RO) and UF. They combine the advantage of low operational pressures with size cut off on the molecular scale. NF is used in waste water treatments, purification of ground and surface waters to produce drinking water, and for RO pretreatment.

Although MBR capital and operational costs somewhat exceed the costs of conventional process, it seems that the upgrade of the conventional process occurs even in cases where conventional treatment works well. It can be related to the increase of water price and the need for water reuse, as well as with the more stringent regulations on effluent quality. [5]

\section{LITERATURE REVIEW}

Chia-Yuan Chang et al. (2008) has done a pilot-scale study of pharmaceutical wastewater treatment by a membrane bioreactor (MBR) process in southern Taiwan. The performance of the MBR was monitored for a period of 140 days. It was demonstrated that the MBR system is capable of removing 95\% and 99\% of COD and BOD5 respectively. The results indicate that the MBR system has a great potential in treating this type of wastewater with stable operation and satisfactory removal performance.[1]

Hernik Wenzel et al. (1996) has worked on water reclamation and reuse in the reactive dyeing of cotton. The research focused on RO, nanofiltration, and tight ultrafiltration membranes. Polysulphone nanofiltration membranes having a negatively charged polyamide coating (presumably carboxylated) were found to have specifically high retentions and very high fluxes, presumably due to repulsion of the negatively charged dyestuff molecules (Donnan effect). The rinse water can be reclaimed by membrane filtration in the nanofiltration and RO range and reused for rinsing purposes.[2-3]

M.Brik et al. (2006) has quantified the performance of a membrane bioreactor (MBR) for the treatment of textile wastewater, and investigated its capability to achieve a water quality meeting reuse criteria. It was demonstrated that the system is largely resistant to changing loading rates and that even at high loading rates efficient COD removal occurs. The apparent sludge yield was very low underlining an additional advantage of the MBR system. Hey concluded with wastewater reclamation 
is intended MBR technology is the method of choice when it is combined with other advanced treatment technologies.[4]

Marine Matosic et al. (2009) has studied the results of treatment of wastewater from the bottling of water and soft drinks with a membrane bioreactor (MBR) pilot plant. MBR successfully removed pollutants measured as COD, BOD and TOC from the wastewater with an efficiency of over $90 \%$. Membrane fouling was more pronounced during the first 10 days of the filtration and then gradually slowed down. The most significant fouling was caused by scale precipitation, which was responsible for $70-80 \%$ of the loss of membrane permeability. After 60 days of continuous filtration, it was possible to restore the original permeability of the membrane through intensive chemical cleaning with hypochlorite, acid and alkaline solutions.[5]

Maryam Takht Ravanchi et al. (2009) has intensely worked on the application of membrane processes in petrochemical industry. Processes such as olefin/paraffin separation, light solvent separation, solvent dewaxing, phenol and aromatic recovery, dehydrogenation, oxidative coupling of methane and steam reforming of methane were discussed in detail. They come up with the conclusion that Based upon large capital expense and energy cost of industrial distillation columns, it seems worthy to recommend membrane processes as a substitution with distillation columns in industrial applications. The application of different membrane reactors to these reactions was investigated and valuable experimental results were obtained as well. In this case, it also seems attractive to consider membrane reactor in industrial applications.[6]

T.Melin et al. (2006) has done a case study on a full-scale MBR plant for municipal wastewater which is operated by Aquafin in Belgium. The presented paper illustrates that MBR technology has a significant potential to become a key element of wastewater reclamation and reuse schemes worldwide. Many areas such as fouling control, pre-treatment, maintenance and operators training have to be established in the operational procedures and drawbacks are expected in the uptake of this technology, which define the need for more intensive and practitioner-oriented research on MBRs.[7]

Wenbo Yang et al. (2006) has critically characterized worldwide academic research efforts in the area of MBRs as well as focus attention to commercial MBR applications in North America. Their study suggests, in contrast to applications for treatment of municipal wastewater, MBR technology is already an attractive option for the treatment of industrial wastewaters that are generally high in pollutant loading but much smaller plant size. Promising areas of expansion include food-processing wastewater, slaughterhouse wastewater and landfill leachates. The research and commercial application of the membrane bioreactor technology are advancing rapidly around the world for both municipal and industrial wastewater treatment. MBR technology is facing some research and development challenges. Among these challenges, membrane fouling is one of the most serious problems that have retarded faster commercialization of MBR technology. If these challenges can be addressed by the research community, MBRs will undoubtedly achieve much wider acceptance.[8-10]

Xianghua Wen et al. (2004) has worked on treatment of hospital wastewater using a sMBR The removal efficiency for COD, NH4+ $-\mathrm{N}$, and turbidity was 80,93 and $83 \%$ respectively with the average effluent quality of COD $<25 \mathrm{mg} / \mathrm{l}, \mathrm{NH} 4+-\mathrm{N}<1.5 \mathrm{mg} / \mathrm{l}$ and turbidity $<3 \mathrm{NTU}$. Escherichia coli removal was over $98 \%$. The effluent had no colour and no odour. The transmembrane pressure increased slowly during 6 months operation. No membrane cleaning operation was used and no sludge was discharged during the 6-month operation period.[10] 


\section{METHODOLOGY}

A)EXISTING METHODOLOGY: Biological treatment technologies have been utilized in wastewater reclamation for over a century. Out of the many different processes employed, the activated sludge system has proven to be most popular. The implementation of membranes within the treatment sequence of a water pollution control facility was initially limited to tertiary treatment and polishing. Ultra-filtration, micro-filtration, or reverse osmosis units were utilized in areas where discharge requirement were very stringent or direct reuse of the effluent was desired (Metcalf \& Eddy 1991). High capital and operational costs as well as inadequate knowledge on membrane application in waste treatment were predominant factors in limiting the domain of this technology. However with the emergence of less expensive and more effective membrane modules and the implementation of evertightening water discharge standard, membrane systems regained interest. Membrane modules have evolved form being utilized solely in tertiary wastewater treatment to being integrated into secondary wastewater treatment. These systems are now most commonly referred to as membrane bioreactors (MBRs). Figure 1.1 summarizes the evolution of membrane use in wastewater treatment and demonstrates the basic differences in the treatment trails. There are several advantages associated with the MBR which make it a valuable alternative over other treatment techniques. First of all, the retention of all suspended matter and most soluble compounds within the bioreactor leads to excellent effluent quality, capable of meeting stringent discharge requirements and opening the door to direct water reuse (Chiemchaisri et al. 1992). The possibility of retaining all bacteria and viruses results in a sterile effluent, eliminating extensive disinfection and the corresponding hazards related to disinfection by-products (Cicek et al. 1998a).
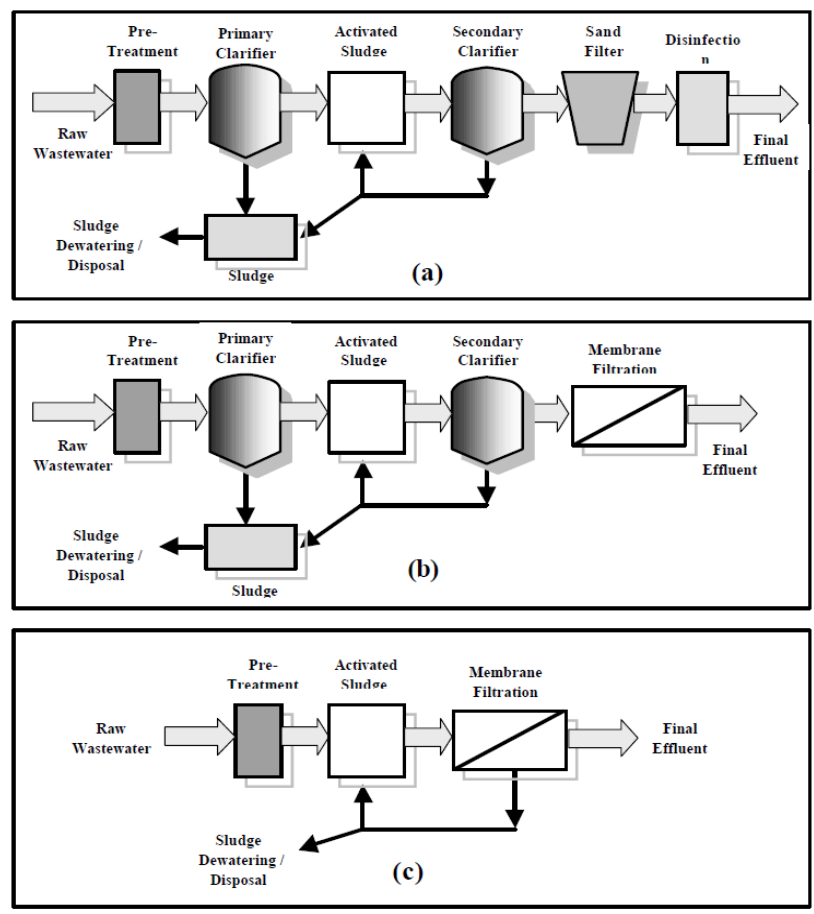

FIG-1.1: Flowcharts for (a) conventional wastewater treatment, (b) conventional treatment including tertiary membrane filtration, and (c) membrane bioreactors.

Since no suspended solids are lost in the clarification step, total separation and control of the solid retention time (SRT) and hydraulic retention time (HRT) is possible enabling optimum control of the microbial population and flexibility in operation. The absence of a clarifier, which also acts as a 
natural selector for settling organisms, enables sensitive, slow-growing species (nitrifying bacteria, bacteria capable of degrading complex compounds) to develop and persist in the system even under short SRTs (Cicek etal. 2001). The membrane not only retains all biomass but also prevents the escape of exocellular enzymes and soluble oxidants creating a more active biological mixture capable of degrading a wider range of carbon sources (Cicek et al. 1999c). MBRs eliminate process difficulties and problems associated with settling, which is usually the most troublesome part of wastewater treatment. The potential for operating the MBRat very high sludge ages without having the obstacle of settling, allows high biomass concentrations in the bioreactor. Consequently, higher strength wastewater can be treated and lower biomass yields are realized (Muller et al. 1995). This also results in more compact systems than conventional processes, significantly reducing plant footprint and making it desirable for water recycling applications. High molecular weightsoluble compounds, which are not readily biodegradable in conventional systems, are retained in the MBR. Thus, their residence time is prolonged and the possibility of oxidation is improved. The system is also a bleto handle fluctuations in nutrient concentrations due to extensive biological acclimation and retention of decaying biomass (Cicek et al. 1999b).

The disadvantages associated with the MBR are mainly cost related. High capital costs due to expensive membrane units and high energy costs due to the need for a pressure gradient have characterized the system. Concentration polarization and other membrane fouling problems can lead to frequent cleaning of the membranes, which stop operation and require clean water and chemicals. Another drawback can be problematic waste activated sludge disposal. Since the MBR retains all suspended solids and most soluble organic matter, waste activated sludge may exhibit poor filterability and settlebility properties (Ciceket al. 1999c). Another limitation of the MBR, when operated at high SRTs, is the possible accumulation ofnon-filterable inorganic compounds in the bioreactor. This can reach concentration levels that can be harmful to the microbial population or membrane structure (Cicek et al. 1999a).The MBR has emerged as an alternative treatment process, especially in cases where space and water resources are limited and high quality product water is required. Industrial wastewater, which is difficult to treat and requires long sludge ages, and wastewater operations where settling and clarification problems are regularly encountered are potential areas of application. With new developments in membrane design and the institution of more stringent discharge limits, MBRs have become feasible alternatives. Membrane bioreactors are composed of two primary parts; the biological unit responsible for the biodegradation of the waste compounds, and the membrane module for the physical separation of the treated water from mixed liquor. MBR systems can be classified into two major groups according to their configuration. The first group, which is also commonly known as the integrated MBR, involves outer skin membranes that are internal to the bioreactor. The driving force across the membrane is achieved by pressurizing the bioreactor or creating negative pressure on the permeate side of the membrane (Buissonet al. 1998; Cote et al. 1997; Rosenberger et al. 2002).

Figure 1.2 presents a simple schematic of the integrated (submerged) MBR.

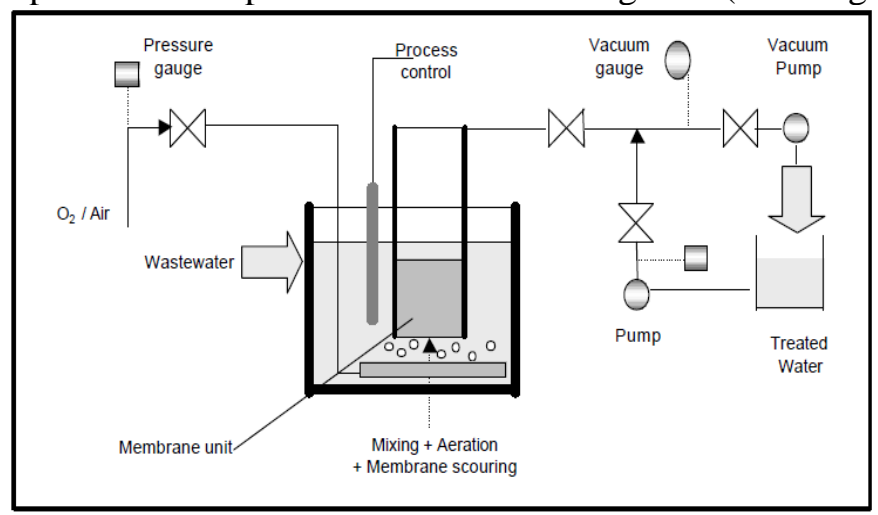


FIG-1.2: Schematic of Integrated (Submerged) MBR.

Cleaning of the membrane is achieved through frequent permeate back-pulsing and occasional chemical backwashing. A diffuser is usually placed directly beneath the membrane module to facilitate air and liquid scouring of the filtration surface. Aeration and mixing are also achieved by the same unit. Anoxicor anaerobic compartments can be incorporated to enable simultaneous biological nutrient removal (Coteet al. 1998).The second configuration is the recirculated (external) MBR, which involves the recirculation of the mixed liquor through a membrane module that is outside to the bioreactor. Both inner-skin and outer-skin membranes can be used in this application. The driving force is the pressure created by high cross flow velocity along the membrane surface (Cicek et al. 1998b; Urbain et al. 1998). A schematic of the recirculated MBR is presented in Figure 1.3.

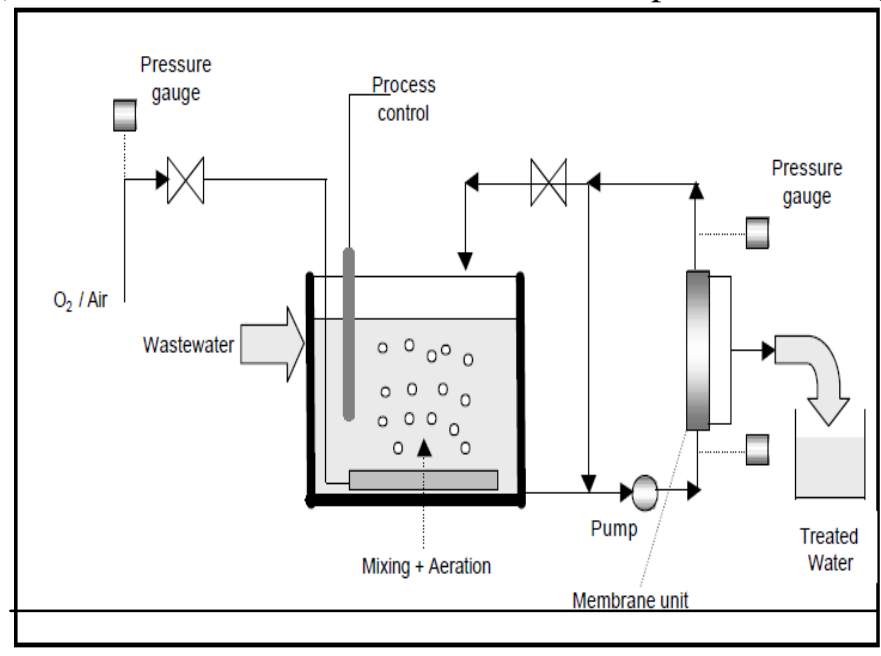

FIG-1.3: Schematic of Recirculated (External) MBR.

The emergence of less expensive and more resilient polymeric membranes along with lower pressure requirements and higher permeate fluxes have accelerated the worldwide commercial use of submerged MBRs (Adham et al. 2001).

Several types and configurations of membranes have been used for MBR applications (Visvanathanet al. 2000). These include tubular, plate and frame, rotary disk, hollow fiber, organic (polyethylene, polyethersulfone, polysulfone, polyolefin, etc), metallic, and inorganic (ceramic) micro-filtration and ultrafiltration membranes. The pore size of the membrane used ranged from $0.01 \mathrm{~mm}$ up to $0.4 \mathrm{~mm}$ (also reported in molecular weight cutoff as 20-2000 kilodalton). The fluxes obtained ranged from 0.05 to $10 \mathrm{~m} / \mathrm{d}$, strongly depending on the configuration and membrane material. Typical values for inner skin membranes are reported as $0.5-2.0 \mathrm{~m} / \mathrm{d}$ and for outer skin membranes as $0.2-0.6 \mathrm{~m} / \mathrm{d}$ at 20 ${ }^{\circ} \mathrm{C}$. Theapplied trans-membrane pressure ranges from 0.2 to 5.0 bar for inner skin membranes and from -0.1 to-0.8 bar for outer skin membranes (Manem and Sanderson 1996).

The membrane used in MBR systems must satisfy several criteria. It must be inert and non biodegradable. It should be easy to clean and regenerate and should be resistant to cleaning agents, high temperatures, and pressures. Uniform pore distribution and high porosity are desired characteristics. The membrane should be neutral or negatively charged to prevent adsorption of microorganisms. Durability and easy replacement are also factors to be considered to reduce operational costs selection. The composition of the biological mixture to be filtered plays a crucial role in the selection of the membrane. For instance, the presence of strong inorganic crystals which can change the composition and structure of the membrane surface through abrasion should be avoided to prolong the life of composite ceramic membranes. In these applications either pretreatment of the 
influent wastewater or the utilization of polymeric membranes are recommended (Cicek et al. 1999a).There are several operating parameters that influence the filtration capacity of the membrane in aMBR. Trans-membrane pressure (TMP), which is the average pressure gradient across the membrane, is linearly related to permeate flux until the filtration cake resistance is dominant. At this point, which is also referred to as the critical TMP, flux becomes independent of applied pressure (Cicek et al. 1998b). The cross flow velocity (CFV) is another parameter that is linearly related to permeate flux. Viscosity of the mixed liquor is also a very important factor in MBR performance. High viscosity affects the hydraulicregime, promotes head loss and increases operation costs. Since viscosity is a function of temperature, the filtration performance is strongly affected by variations in mixed liquor temperature. The physiological state of the biomass can significantly impact the filtration performance of the membrane. The community structure in the bioreactor influences the extent of flocculation, charge and structure of cells, and the concentration of exo-polymeric substances (EPS). It has been shown previously, that the extent of floc formation is directly related to the concentration of EPS, which influence the structure of the filter cake and the extent of fouling (Manem and Sanderson 1996). A strong correlation between soluble organic compounds, particularly soluble sugars and proteins, and permeate flux was established in a long term study conducted by the author (Cicek et al. 2002). Organic compounds smaller than $0.10 \mathrm{~mm}$ in size exhibited the strongest impact on filtration performance. Therefore, extensive membrane fouling and the need for frequent regeneration can be reduced if conditions favorable to enhanced biodegradation and less EPS formation are created. It quickly becomes apparent that the design of MBR systems involves the consideration of many factors. These factors can be biological, physical, or hydrodynamic in nature. Understanding the role of each of these parameters and their interactions is essential for effective design, optimization, and cost analysis of this technology.

\section{B) PROPOSED METHODOLOGY:}

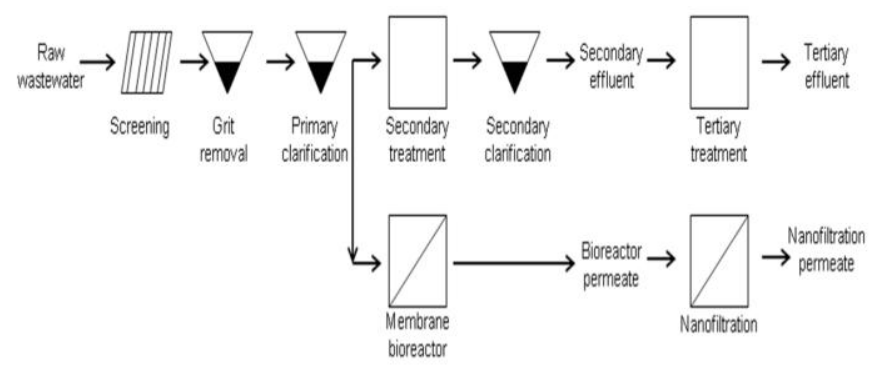

FIG. 1.4: Conventional wastewater treatment stages and an alternative membrane-based process scheme.

Sources for water reuse are not only effluents from industries, but also those from municipal waste water treatment plants (WWTPs). Municipal effluents can be more easily reused and retransformed for instance into drinking water as their pollution is more straight forward and the type of pollution does not change dramatically over time. Also the pollution is usually not as hard to treat as that present in industrial wastewaters. Still, the contact of human beings with reused water from any type of wastewater faces psychological barriers and negative perception that make it difficult to introduce valuable water reuse concepts. However, high quality municipal wastewater effluents can be obtained by upgrading conventional WWTPs with membrane technologies such as membrane bioreactors (MBRs)for secondary treatment as well as nano filtration (NF) for tertiary polishing (Fig. 1.4). Those 
membrane concepts have the potential to deliver clean water that can be reused in agriculture, industry or sanitation and as such contribute to a sustainable global water supply.

In a conventional treatment plant, the raw municipal wastewater (containing mainly e.g.proteins, carbohydrates, fats and oils as organic pollutants) first passes coarse screens $(6-150 \mathrm{~mm})$ to remove large floating objects, followed by a grit removal stage to separate heavier material (e.g. stones, metal) to protect further treatment stages [8]. After that the wastewater proceeds to the primary clarification stage. Here the first separation of suspended particles and water takes place. The water passes large circular or rectangular clarificationtanks at low speed, giving the solids time to settle to achieve the separation. This primary treatment removes about 50-70\% of the total suspended solids (TSS) and 25$40 \%$ of the biological oxygen demand (BOD) [8]. After the solids settled the remaining primary waste sludge, resulting from the primary clarification process, is further processed in sludge treatment facilities on site. The water itself proceeds through overflows to the secondary treatment stage. In this stage, conventional activated sludge (CAS) systems are commonly used. Different configurations are possible but the main targets are the removal of organic substances (quantified as chemical oxygen demand (COD) or biological oxygen demand (BOD)), as well as nutrient ( $\mathrm{N}$ and $\mathrm{P}$ ) removal. $\mathrm{COD} / \mathrm{BOD} 5$ removal is performed by heterotrophic bacterial community in the activated sludge. In the so-called aerobic stage in the secondary treatment, an aeration system supplies oxygen into the liquid via diffused-air or mechanical aerators. The presence of oxygen allows the bacteria to oxidize the organic material to $\mathrm{CO} 2$ and water. Also nitrogen removal is performed in this secondary stage. The transformation of ammonium to nitrate (nitrification) by autotrophic nitrifiers (e.g. Nitrosomonas, Nitrobacter) is followed by an anaerobic (anoxic) process, where mainly heterotrophic bacteria reduce nitrate into $\mathrm{N} 2$, which is released into the atmosphere. In addition to nitrogen, also phosphorous is removed in this secondary stage. This is done either chemically by precipitation, or biologically by enhanced biological phosphorous removal(EBPR). After the secondary stage, another clarification step is needed to separate the suspended solids (activated sludge) from the water. The settled sludge is (partly) recirculated back to the activated sludge tank. The waste sludge is treated further in the sludge treatment facility on site, where the sludge is dewatered. The clean water on the other hand slowly passes the large secondary clarification tanks and can either be discharged into the environment or can be polished further by tertiary treatment for water reuse. Besides the option of filtration that is elaborated on in this work, also adsorption, ion exchange as well as advanced oxidation processes [9, 10] can be used. Their use is very much dependent on the requirements and final reuse application of the water. Membranes cannot only be applied in tertiary polishing, but also offer several advantages already in the secondary wastewater treatment stage. As shown in Figure 1.4, the secondary treatment (CAS) in the conventional process can be replaced by an MBR using porous low pressuremicro- or ultra-filtration membranes, while for the tertiary treatment and polishing step, NF can be applied. Figure 1.5 gives an overview of existing membrane types for water treatment and their corresponding rejection behavior of common pollutants .

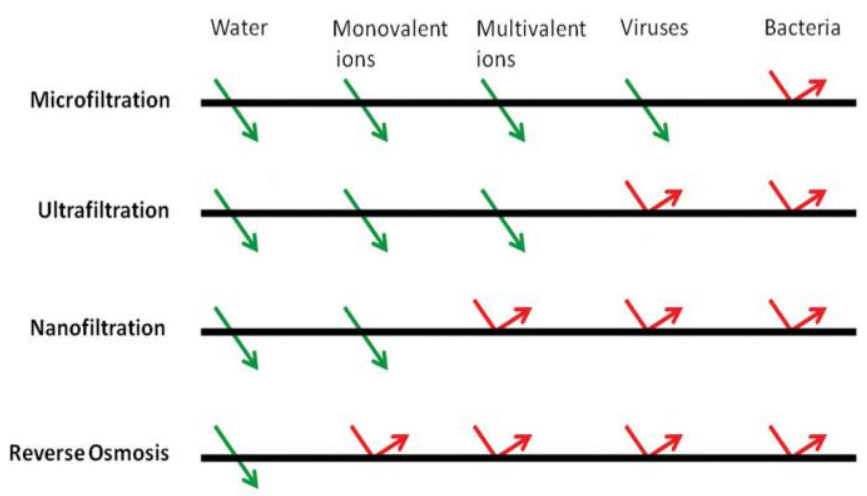

FIG. 1.5:Overview of membrane separation processes and ranges of compound rejections 
(adapted from [11]).

C) ADVANTAGES OF PROPOSED METHODOLOGY:

1. The MBR resembles a reasonable treatment option in combination with other advanced treatment technologies to achieve reuse standards. In particular the permeate is suitable to be directly fed to a nanofiltration.

2. The recovery of minor but valuable components from a main stream using membranes can be done without substantial additional energy costs.

3. These systems have compact size, modular configuration, and low specific power consumption, which reduce the production cost.

4. It is an eco friendly, clean process and requires simple and inexpensive filtration.

5. The continued push towards stricter discharge standards, increased requirement for water re-use and greater than before urbanization and land limitations will further fuel the use of MBRs and it's hybrid modules.

6. With recovery of valuable industrial by products and environmental protection a sustainable development in the industries and the environment can be achieved.

\section{CONCLUSION}

Future research on this integrated MBR NF membrane concept with concentrate recirculation and nutrient recovery is possible. The process produces high quality, reusable water as the NF permeate, and at the same time reduces the amount of concentrated waste and even allows the recovery of valuable components. Nevertheless, the use of two membrane systems can be energy and especially maintenance intensive. Also, the decreased sludge production and increased membrane fouling raise some challenges. More research regarding additional sludge treatment facilities, the use of different membrane types and configurations as well as the quality and separation of the obtained calcium phosphates is suggested. The concept is very attractive for micro pollutant removal and more detailed research on the behavior of specific emerging micro pollutants in the MBR NF process with concentrate recirculation is important.

\section{References}

[1] Chia-Yuan Changa, Jing-Song Changa, Saravanamuthu Vigneswaranb,Jaya Kandasamy, "Pharmaceutical wastewater treatment by membrane bioreactor process - a case study in southern Taiwan", Desalination 234 (2008) 393-401.

[2] Henrik Wenzel, Hans Henrik Knudsen, Gert Holm Kristensen, John Hansen, "Reclamation and reuse of process water from reactive dyeing of cotton, Desalination 106 (1996) 195-203.

[3] Hong-Zhang Wu, Yu-Lan Hsu, Yi-Jong Lee, P-Hsiu-Ping Lin, "Reclamation of textile dyeing wastewater for process use via a highly efficient integration system", Desalination 172 (2005) 293-307.

[4] M. Brik, P. Schoeberl, B. Chamam, R. Braun, W. Fuchs, "Advanced treatment of textile wastewater towards reuse using a membrane bioreactor, Process Biochemistry 41 (2006) 17511757.

[5] Marin Matošić, Ivana Prstec, Helena Korajlija Jakopović, Ivan Mijatović, "Treatment of beverage production wastewater by membrane bioreactor", Desalination 246 (2009) 285-293.

[6] Maryam Takht Ravanchi, Tahereh Kaghazchi, Ali Kargari, "Application of membrane separation processes in petrochemical industry: a review", Desalination 235 (2009) 199-244.

[7] T. Melina, B. Jeffersonb, D. Bixioc, C. Thoeyec, W. De Wildec, J. De Koningd,J. van der Graaf $\mathrm{d}$ and T. Wintgens, "Membrane bioreactor technology for wastewater treatment and reuse", Desalination 187 (2006) 271-282. 
[8] Wenbo Yang a, Nazim Cicek a, John Ilg, "State-of-the-art of membrane bioreactors: Worldwide research and commercial applications in North America", Journal of Membrane Science 270 (2006) 201-211.

[9] Xianghua Wen, Hangjiu Ding, Xia Huang, Ruopeng Liu, "Treatment of hospital wastewater using a submerged membrane bioreactor", Process Biochemistry 39 (2004) 1427-1431.

[10] Zhiwei Wang, Zhichao Wu, Suihai Maib, Caifeng Yang, Xinhua Wang, Ying Ana, Zhen Zhou, "Research and applications of membrane bioreactors in China: Progress and prospect", Separation and Purification Technology 62 (2008) 249-263.

[11] Stacy Scott, Application of Membrane Bioreactor Technology to Waste Water Treatment and Reuse.

[12] P. Malathi \& R. Viswanathan, "Role of Microbial Chitinase in the Biocontrol of Sugarcane Red Rot Caused by Colletotrichum falcatum Went",www.ejarr.com/Volumes/Vol6/EJBS_6_04, EJBS 6 (1), Jan 2013.

[13] Mason, C.A., Hamer, G., Fleischmann, T., Lang, C., 1987. Aerobic thermophilic biodegradation of microbial cells. Applied Microbiology and Biotechnology 25 (6),568-576.

[14] In-Soung Chang; Pierre Le Clech; Bruce Jefferson; and Simon Judd, "Membrane Fouling in Membrane Bioreactors for Wastewater Treatment" 1018, journal of environmental engineering, november 2002.

[15] N. Cicek, "Membrane Bioreactors in the Treatment of Wastewater Generated from Agricultural Industries and Activities" Written for presentation at the AIC 2002 Meeting CSAE/SCGR Program Saskatoon, Saskatchewan, July 14 - 17, 2002.

[16] Hai, F. I. \& Yamamoto, K. (2011). Membrane Biological Reactors. In P. Wilderer (Eds.), Treatise on Water Science (pp. 571-613), UK: Elsevier.

[17] M. Lerner, N. Stahl and N.I. Galil, "Comparative study of MBR and activated sludge in the treatment of paper mill wastewater", Water Science \& Technology Vol 55 No 6 pp 23-29 , IWA Publishing 2007.

[18] Fu Guokai, Zhou Qi, Yu Jian, "Removal of Organic Matter and Nitrogen in Municipal Wastewater by a New Submerged Membrane Bioreactor" http://www.paper.edu.cn

[19] LI Gang, WU Lin-lin, DONG Chun-song, WU Guang-xia, FAN Yao-bo, "Inorganic nitrogen removal of toilet wastewater with an airlift external circulation membrane bioreactor" Journal of Environmental Sciences 19(2007) pp: 12-17.

[20] Jian-Jun Qin, Maung Htun Oo, Guihe Tao, Kiran A. Kekre, "Pilot study of a submerged membrane bioreactor for water reclamation", Water Science \& Technology-WST, 60.12 , 2009.

[21] J.P. van der Hoek, Combined ion exchange/biological denitrification for nitrate removal from ground water.

[22] Ganczarczyk, J., Hamoda, M.F., Hong-Lit, Wong, 1980. Performance of aerobic digestion at different sludge solid levels and operation patterns. Water Research 14 (6), 627-633.

[23] Tyagi, R.D., Trab, F.T., Agbebavi, T.J., 1990. Mesophilic and thermophilic aerobic digestion of municipal sludge in an airlift U-shape bioreactor. Biological Wastes 31 (4), 251-266.

[24] S.C.Bhatia, "Environmental Pollution and Control in Chemical Process Industries" pp:590-606 (2005).

[25] NEERI, "Wastewater analysis and Treatment" pp:112-116(2001).

[26] EPRI Municipal Water and Wastewater Program, "Techcommentry” pp: 1-6(1997).

[27] Santos Chicas, "Study on cleaner production opportunities for sugar industry in Belize", pp: 14-20, 79-103(June 2008).

[28] H. Al-Zoubi, S. Al-Thyabat, L. Al-Khatib " A hybrid flotation-membrane process for wastewater treatment: an overview" (August 2008).

[29] Robert Bastian, Bob Brobst, "Environmental regulations and technology pp: 43-44,(Oct 1999). 
[30] Enrico Drioli, "Springer-Verlag, Process Intensification Using Membrane System”, pp: 3-4, (February 2003).

[31] Deborah Bohot, "Membrane Thickners in Controlled Aerobic Disgetion", (2000).

[32] Dr. Rafael Munoz Candelario, Dr. Felix D.Santiago, "Treatment of Liquid Waste from Cane sugar Industry", (June 1974).

[33] Alyson Sagle and Benny Freeman, "Fundamentals of Membrane for Water Treatment", pp:110.

[34] Andrzej I. Stankiewicz, Jacob A. Moulijn, "Chemical Engineering Progress",pp: 22-32 (January 2000).

[35] S. P. Nunes and K. V Peivemann, "memrbrane technology in chemical industry", pp: 16-24 (2001).

[36] Christina Kappel, "An Integrated Membrane Bioreactor - Nanofiltration Concept With Concentrate Recirculation For Wastewater Treatment And Nutrient Recovery", PhD Thesis, University of Twente, ISBN: 978-90-365-3640-0J. K. Author, "Title of chapter in the book," in Title of His Publisis Published Book, $x$ th ed. City of Publisher, Country if not 